\title{
An exact solution for the three-phase piezoelectric cylinder model under antiplane shear and its applications to piezoelectric composites
}

\author{
C.P. Jiang ${ }^{\mathrm{a}, \mathrm{b}}$, Y.K. Cheung ${ }^{\mathrm{c}, *}$ \\ ${ }^{\text {a }}$ LNM, Institute of Mechanics, Chinese Academy of Sciences, Beijing 100080, People's Republic of China \\ ${ }^{\mathrm{b}}$ Department of Flight Vehicle Design and Applied Mechanics, Beijing University of Aeronautics and Astronautics, Beijing 100083, \\ People's Republic of China \\ ${ }^{\mathrm{c}}$ Department of Civil Engineering, The University of Hong Kong, Pokfulam Road, Hong Kong, Hong Kong \\ Received 30 September 1998; in revised form 5 August 2000
}

\begin{abstract}
A three-phase piezoelectric cylinder model is proposed and an exact solution is obtained for the model under a farfield antiplane mechanical load and a far-field inplane electrical load. The three-phase model can serve as a fiber/interphase layer/matrix model, in terms of which a lot of interesting mechanical and electrical coupling phenomena induced by the interphase layer are revealed. It is found that much more serious stress and electrical field concentrations occur in the model with the interphase layer than those without any interphase layer. The three-phase model can also serve as a fiber/matrix/composite model, in terms of which a generalized self-consistent approach is developed for predicting the effective electroelastic moduli of piezoelectric composites. Numerical examples are given and discussed in detail. (c) 2001 Elsevier Science Ltd. All rights reserved.
\end{abstract}

Keywords: Piezoelectric composites; Micromechanics; Effective electroelastic moduli; Generalized self-consistent method; Complex variable method

\section{Introduction}

Piezoelectric composites have become an important branch of modern engineering materials with the recent development of the intelligent materials and structures (see e.g. Gandhi and Thompson, 1992). The micromechanics of piezoelectric composite materials has attracted a great deal of attention for its application in understanding the mechanical and electrical coupling behavior of such materials as well as in predicting their effective electroelastic moduli. The references listed herein (Honein et al., 1990; Sosa, 1991; Wang, 1992; Pak, 1992; Dunn and Taya, 1993; Benveniste, 1993; Zhang et al., 1998) are some examples of the contributions in this area. However such existing micromechanics models for piezoelectric (composite)

\footnotetext{
${ }^{*}$ Corresponding author. Tel.: +852-2859-2668; fax: +852-2559-5337.

E-mail address: hreccyk@hkucc.hku.hk (Y.K. Cheung).
} 
materials are all two-phase models of inclusion (cavity)/matrix. For non-piezoelectric composites the threephase models of inclusion/matrix/composite (Christensen and Lo, 1979; Luo and Weng, 1987, 1989; Huang et al., 1994; Huang and $\mathrm{Hu}, 1995$; Jiang and Cheung, 1998) are developed as an extension of Eshelby's ellipsoidal inclusion model (Eshelby, 1957, 1959). In estimating the effective moduli of composite materials, the three-phase models provide accurate predictions that are well suited for extreme types of inclusions (from voids to rigid inclusions), and the method also gives the correct asymptotic behavior of composites as the inclusion volume fraction approaches 1 (fully packed). Besides, the three-phase models can also be used to study stress and electric field concentrations in piezoelectric composites accounting for interphase layers between the inclusion and matrix. So it is highly desirable that the three-phase model is further applied to study piezoelectric composites.

In this paper a three-phase piezoelectric cylinder model is proposed, and an exact solution is obtained for the case of a far-field antiplane mechanical load and a far-field inplane electrical load by using the complex potentials for electroelastic materials integrated with the Laurent expansion technique. Subsequently, this micromechanics model is applied to the investigation of piezoelectric composites. First the three-phase model serves as a fiber/interphase layer/matrix model, which are used to study stress and electrical field concentrations induced by the interphase layers. The three-phase model also serves as a fiber/matrix/ composite model, in terms of which a generalized self-consistent approach is developed for predicting effective electroelastic moduli of such materials. Numerical examples based on the model are given and discussed, and it can be seen that several classical models and solutions are special cases of the present model and solution.

\section{Model and basic formulation}

A cross-section of the three-phase cylindrically concentric piezoelectricity model is depicted in Fig. 1. A circular piezoelectric fiber is embedded in the intermediate piezoelectric material annulus (the second-phase material) which, in turn, is embedded in an infinite outer piezoelectric material (the third-phase material). The three-phase piezoelectric materials occupy the regions $\Omega_{1}, \Omega_{2}$ and $\Omega_{3}$, respectively. They are assumed to have different material properties, but to have the same material orientation in that they have all been poled along the $x_{3}$-direction with an isotropic $O x_{1} x_{2}$-plane.

Letting the model be subjected to a far-field antiplane shear and a far-field inplane electrical field, then only the out-of-plane displacement coupled with the inplane electrical field need be considered so that there are only the non-trivial displacement $w$, strains $\gamma_{13}$ and $\gamma_{23}$, stresses $\tau_{13}$ and $\tau_{23}$, electrical potential $\phi$, electrical field components $E_{1}$ and $E_{2}$, and electrical displacement components $D_{1}$ and $D_{2}$. The straindisplacement relations can be written as:

$$
\gamma_{13}=\frac{\partial w}{\partial x_{1}}, \quad \gamma_{23}=\frac{\partial w}{\partial x_{2}}
$$

and the electrical field is related to the electrical potential by

$$
E_{1}=-\frac{\partial \varphi}{\partial x_{1}}, \quad E_{2}=-\frac{\partial \varphi}{\partial x_{2}}
$$

The mechanical and electrical coupled constitutive equations (Tiersten, 1969) can be expressed as

$$
\begin{array}{ll}
\tau_{13}=C_{44} \frac{\partial w}{\partial x_{1}}+e_{15} \frac{\partial \varphi}{\partial x_{1}}, & \tau_{23}=C_{44} \frac{\partial w}{\partial x_{2}}+e_{15} \frac{\partial \varphi}{\partial x_{2}} \\
D_{1}=e_{15} \frac{\partial w}{\partial x_{1}}-d_{11} \frac{\partial \varphi}{\partial x_{1}}, & D_{2}=e_{15} \frac{\partial w}{\partial x_{2}}-d_{11} \frac{\partial \varphi}{\partial x_{2}}
\end{array}
$$




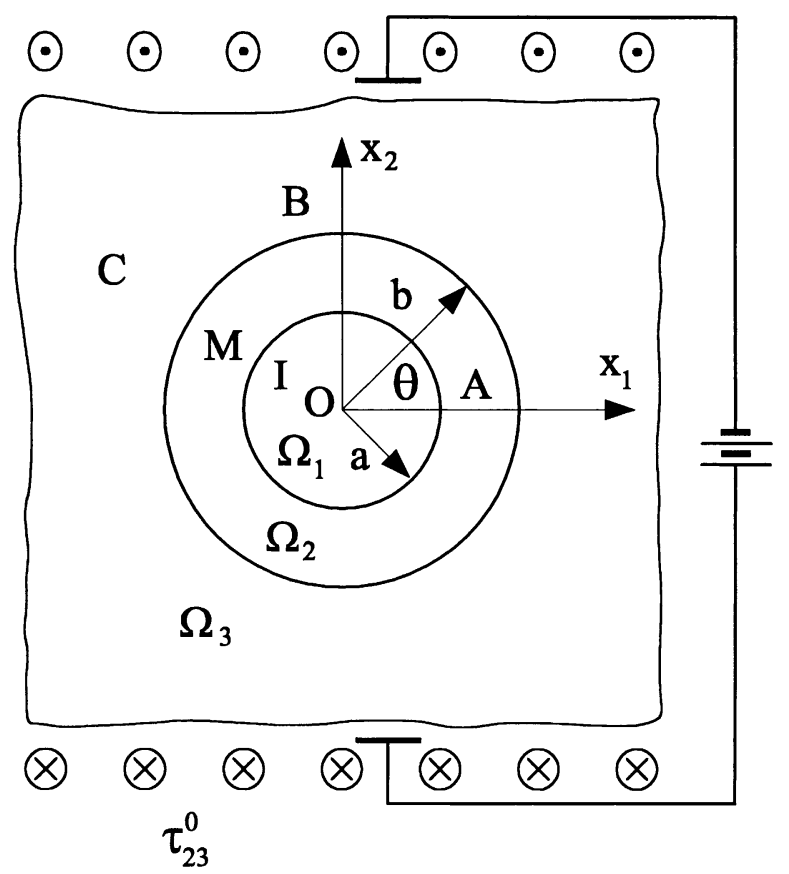

Fig. 1. Schematic diagram of a three-phase piezoelectric cylinder model.

where $C_{44}$ is the longitudinal shear modulus at a constant electric field, $e_{15}$ is the piezoelectric modulus, $d_{11}$ is the dielectric modulus at a constant stress field. The equilibrium equation and charge equation (Tiersten, 1969) can be reduced to the harmonic equations:

$$
\nabla^{2} w=0, \quad \nabla^{2} \varphi=0
$$

where $\nabla^{2}=\left(\partial^{2} / \partial x_{1}^{2}\right)+\left(\partial^{2} / \partial x_{2}^{2}\right)$ is the Laplace operator.

Eq. (5) shows that the general solutions of $w$ and $\varphi$ can be expressed by analytical functions or complex potentials $\Psi(z)$ and $\Phi(z)$, respectively, where the complex variable $z=x_{1}+\mathrm{i} x_{2}$

$$
w=\operatorname{Re} \Psi(z), \quad \varphi=\operatorname{Re} \Phi(z)
$$

where Re denotes the real part of a complex function. The constitutive equations can also be cast into complex form:

$$
\begin{aligned}
& \tau_{13}-\mathrm{i} \tau_{23}=C_{44} \Psi^{\prime}(z)+e_{15} \Phi^{\prime}(z) \\
& D_{1}-\mathrm{i} D_{2}=e_{15} \Psi^{\prime}(z)-d_{11} \Phi^{\prime}(z)
\end{aligned}
$$

where the superscript prime denotes the differentiation with respect to the argument.

The following definitions are adopted in order to facilitate the analysis.

$$
\begin{aligned}
& T_{\tau}=-\int_{A}^{B}\left(\tau_{23} \mathrm{~d} x_{1}-\tau_{13} \mathrm{~d} x_{2}\right)=\operatorname{Im}\left[C_{44} \Psi(z)+e_{15} \Phi(z)\right]_{A}^{B} \\
& T_{D}=-\int_{A}^{B}\left(D_{2} \mathrm{~d} x_{1}-D_{1} \mathrm{~d} x_{2}\right)=\operatorname{Im}\left[e_{15} \Psi(z)-d_{11} \Phi(z)\right]_{A}^{B}
\end{aligned}
$$


where Im denotes the imaginary part of a complex function, $[\cdot]_{A}^{B}$ signifies the change in the bracketed function in moving from point $A$ to point $B$ along any arc $A B$.

The assumption of perfect bonding between adjacent phases of the model enforces continuity of displacements, electrical potentials, stresses and electrical displacements across the interphases, which lead to the following continuity conditions:

$$
\begin{array}{ll}
w^{\mathrm{I}}=w^{\mathrm{M}}, & \varphi^{\mathrm{I}}=\varphi^{\mathrm{M}}, \quad T_{\tau}^{\mathrm{I}}=T_{\tau}^{\mathrm{M}}, \quad T_{D}^{\mathrm{I}}=T_{D}^{\mathrm{M}} \quad \text { on } r=a \\
w^{\mathrm{M}}=w^{\mathrm{C}}, \quad \varphi^{\mathrm{M}}=\varphi^{\mathrm{C}}, \quad T_{\tau}^{\mathrm{M}}=T_{\tau}^{\mathrm{C}}, \quad T_{D}^{\mathrm{M}}=T_{D}^{\mathrm{C}} \quad \text { on } r=b
\end{array}
$$

where the superscripts $\mathrm{I}, \mathrm{M}$, and $\mathrm{C}$ refer to the piezoelectric fiber (inclusion), intermediate piezoelectric material (matrix) and outer (composite) phase of the model, respectively; $a$ and $b$ are the radii of the corresponding two circular interfaces.

\section{Analysis and solution}

In an annular regions the complex potentials $\Psi(z)$ and $\Phi(z)$ can be expanded into Laurent series:

$$
\Psi(z)=a^{*} \ln z+\sum_{k=-\infty}^{\infty} a_{k} z^{k}, \quad \Phi(z)=b^{*} \ln z+\sum_{k=-\infty}^{\infty} b_{k} z^{k}
$$

where $a^{*}, b^{*}, a_{k}$ and $b_{k}$ are complex constants to be determined.

Without loss of generality, let the far-field shear stress $\left.\tau_{13}\right|_{|z| \rightarrow \infty}=0$ and the far-field electrical field $\left.E_{1}\right|_{|z| \rightarrow \infty}=0$, it is seen that taking the following finite terms of the series can arrive at the exact solution:

$$
\begin{aligned}
& \Psi^{\mathrm{I}}=\mathrm{i} A^{\mathrm{I}} z, \quad \Phi^{\mathrm{I}}=\mathrm{i} B^{\mathrm{I}} z \quad \text { in } \Omega_{1} \\
& \Psi^{\mathrm{M}}=\mathrm{i}\left(A_{-1}^{\mathrm{M}} \frac{1}{z}+A_{1}^{\mathrm{M}} z\right), \quad \Phi^{\mathrm{M}}=\mathrm{i}\left(B_{-1}^{\mathrm{M}} \frac{1}{z}+B_{1}^{\mathrm{M}} z\right) \quad \text { in } \Omega_{2} \\
& \Psi^{\mathrm{C}}=\mathrm{i}\left(A_{-1}^{\mathrm{C}} \frac{1}{z}+A_{1}^{\mathrm{C}} z\right), \quad \Phi^{\mathrm{C}}=\mathrm{i}\left(B_{-1}^{\mathrm{C}} \frac{1}{z}+B_{1}^{\mathrm{C}} z\right) \quad \text { in } \Omega_{3}
\end{aligned}
$$

where $A^{\mathrm{I}}, B^{\mathrm{I}}, A_{-1}^{\mathrm{M}}, A_{1}^{\mathrm{M}}, B_{-1}^{\mathrm{M}}, B_{1}^{\mathrm{M}}, A_{-1}^{\mathrm{C}}, A_{1}^{\mathrm{C}}, B_{-1}^{\mathrm{C}}$ and $B_{1}^{\mathrm{C}}$ are real constants. $A_{1}^{\mathrm{C}}$ and $B_{1}^{\mathrm{C}}$ can be determined by the far-field conditions. Let

$$
\left.\tau_{23}\right|_{|z| \rightarrow \infty}=\tau_{23}^{0},\left.\quad D_{2}\right|_{|z| \rightarrow \infty}=D_{2}^{0}
$$

then from Eqs. (7), (8), (16) and (17), one obtain

$$
-C_{44}^{\mathrm{C}} A_{1}^{\mathrm{C}}-e_{15}^{\mathrm{C}} B_{1}^{\mathrm{C}}=\tau_{23}^{0}, \quad-e_{15}^{\mathrm{C}} A_{1}^{\mathrm{C}}+d_{11}^{\mathrm{C}} B_{1}^{\mathrm{C}}=D_{2}^{0}
$$

The solution of the above algebraic equation system is

$$
A_{1}^{\mathrm{C}}=-\frac{d_{11}^{\mathrm{C}} \tau_{23}^{0}+e_{15}^{\mathrm{C}} D_{2}^{0}}{C_{44}^{\mathrm{C}} d_{11}^{\mathrm{C}}+\left(e_{15}^{\mathrm{C}}\right)^{2}}, \quad B_{1}^{\mathrm{C}}=-\frac{e_{15}^{\mathrm{C}} \tau_{23}^{0}-C_{44}^{\mathrm{C}} D_{2}^{0}}{C_{44}^{\mathrm{C}} d_{11}^{\mathrm{C}}+\left(e_{15}^{\mathrm{C}}\right)^{2}}
$$

Instead of Eq. (17), if the far-field stress and electrical field conditions are prescribed, i.e. let

$$
\left.\tau_{23}\right|_{|z| \rightarrow \infty}=\tau_{23}^{0},\left.\quad E_{2}\right|_{|z| \rightarrow \infty}=E_{2}^{0}
$$


then

$$
A_{1}^{\mathrm{C}}=-\frac{\tau_{23}^{0}+e_{15}^{\mathrm{C}} E_{2}^{0}}{C_{44}^{\mathrm{C}}}, \quad B_{1}^{\mathrm{C}}=E_{2}^{0}
$$

Substituting expansions (14) and (15) into Eqs. (6), (9) and (10), then substituting them into the continuity conditions (11), we obtain four algebraic equations and determine the following relation between the constants corresponding to the inclusion and matrix:

$$
\begin{array}{ll}
A_{1}^{\mathrm{M}}=P_{1} A^{\mathrm{I}}+P_{2} B^{\mathrm{I}}, & A_{-1}^{\mathrm{M}}=a^{2}\left(P_{1}-1\right) A^{\mathrm{I}}+a^{2} P_{2} B^{\mathrm{I}} \\
B_{1}^{\mathrm{M}}=P_{3} A^{\mathrm{I}}+P_{4} B^{\mathrm{I}}, & \mathrm{B}_{-1}^{\mathrm{M}}=a^{2} P_{3} A^{\mathrm{I}}+a^{2}\left(P_{4}-1\right) B^{\mathrm{I}}
\end{array}
$$

where

$$
\begin{aligned}
& P_{1}=\left[\left(C_{44}^{\mathrm{M}}+C_{44}^{\mathrm{I}}\right) d_{11}^{\mathrm{M}}+\left(e_{15}^{\mathrm{M}}+e_{15}^{\mathrm{I}}\right) e_{15}^{\mathrm{M}}\right] / \Delta \\
& P_{2}=\left(e_{15}^{\mathrm{I}} d_{11}^{\mathrm{M}}-e_{15}^{\mathrm{M}} d_{11}^{\mathrm{I}}\right) / \Delta \\
& P_{3}=\left(C_{44}^{\mathrm{I}} e_{15}^{\mathrm{M}}-C_{44}^{\mathrm{M}} e_{15}^{\mathrm{I}}\right) / \Delta \\
& P_{4}=\left[\left(e_{15}^{\mathrm{M}}+e_{15}^{\mathrm{I}}\right) e_{15}^{\mathrm{M}}+\left(d_{11}^{\mathrm{M}}+d_{11}^{\mathrm{I}}\right) C_{44}^{\mathrm{M}}\right] / \Delta \\
& \Delta=2\left[C_{44}^{\mathrm{M}} d_{11}^{\mathrm{M}}+\left(e_{15}^{\mathrm{M}}\right)^{2}\right]
\end{aligned}
$$

Similarly, the continuity conditions (12) at $r=b$ yields four algebraic equations, in terms of which following solution is obtained

$$
\begin{aligned}
& A_{-1}^{\mathrm{C}}=\left[\left(a^{2}-b^{2}\right) P_{1}-a^{2}\right] A^{\mathrm{I}}+\left(a^{2}-b^{2}\right) P_{2} B^{\mathrm{I}}+b^{2} A_{1}^{\mathrm{C}} \\
& B_{-1}^{\mathrm{C}}=\left(a^{2}-b^{2}\right) P_{3} A^{\mathrm{I}}+\left[\left(a^{2}-b^{2}\right) P_{4}-a^{2}\right] B^{\mathrm{I}}+b^{2} B_{1}^{\mathrm{C}} \\
& A^{\mathrm{I}}=\frac{2 b^{2}\left(C_{44}^{\mathrm{C}} Q_{4}-e_{15}^{\mathrm{C}} Q_{2}\right) A_{1}^{\mathrm{C}}+2 b^{2}\left(e_{15}^{\mathrm{C}} Q_{4}+d_{11}^{\mathrm{C}} Q_{2}\right) B_{1}^{\mathrm{C}}}{Q_{1} Q_{4}-Q_{2} Q_{3}} \\
& B^{\mathrm{I}}=-\frac{2 b^{2}\left(C_{44}^{\mathrm{C}} Q_{3}-e_{15}^{\mathrm{C}} Q_{1}\right) A_{1}^{\mathrm{C}}+2 b^{2}\left(e_{15}^{\mathrm{C}} Q_{3}+d_{11}^{\mathrm{C}} Q_{1}\right) B_{1}^{\mathrm{C}}}{Q_{1} Q_{4}-Q_{2} Q_{3}}
\end{aligned}
$$

where

$$
\begin{aligned}
& Q_{1}=\left(C_{44}^{\mathrm{M}}-C_{44}^{\mathrm{C}}\right) a^{2}\left(P_{1}-1\right)+\left(C_{44}^{\mathrm{M}}+C_{44}^{\mathrm{C}}\right) b^{2} P_{1}+\left(e_{15}^{\mathrm{M}}-e_{15}^{\mathrm{C}}\right) a^{2} P_{3}+\left(e_{15}^{\mathrm{M}}+e_{15}^{\mathrm{C}}\right) b^{2} P_{3} \\
& Q_{2}=\left(C_{44}^{\mathrm{M}}-C_{44}^{\mathrm{C}}\right) a^{2} P_{2}+\left(C_{44}^{\mathrm{M}}+C_{44}^{\mathrm{C}}\right) b^{2} P_{2}+\left(e_{15}^{\mathrm{M}}-e_{15}^{\mathrm{C}}\right) a^{2}\left(P_{4}-1\right)+\left(e_{15}^{\mathrm{M}}+e_{15}^{\mathrm{C}}\right) b^{2} P_{4} \\
& Q_{3}=\left(e_{15}^{\mathrm{M}}-e_{15}^{\mathrm{C}}\right) a^{2}\left(P_{1}-1\right)+\left(e_{15}^{\mathrm{M}}+e_{15}^{\mathrm{C}}\right) b^{2} P_{1}-\left(d_{11}^{\mathrm{M}}-d_{11}^{\mathrm{C}}\right) a^{2} P_{3}-\left(d_{11}^{\mathrm{M}}+d_{11}^{\mathrm{C}}\right) b^{2} P_{3} \\
& Q_{4}=\left(e_{15}^{\mathrm{M}}-e_{15}^{\mathrm{C}}\right) a^{2} P_{2}+\left(e_{15}^{\mathrm{M}}+e_{15}^{\mathrm{C}}\right) b^{2} P_{2}-\left(d_{11}^{\mathrm{M}}-d_{11}^{\mathrm{C}}\right) a^{2}\left(P_{4}-1\right)-\left(d_{11}^{\mathrm{M}}+d_{11}^{\mathrm{C}}\right) b^{2} P_{4}
\end{aligned}
$$

By now all the unknown coefficients in the expressions of the complex potentials (14)-(16) have been determined exactly, and the various mechanical and electrical quantities for the problem under consideration can be easily obtained from the corresponding equations. The stress field, electrical field and electrical displacement fields in the fiber and annulus intermediate material are as follows: 


$$
\begin{aligned}
& \tau_{23}^{\mathrm{I}}=-C_{44}^{\mathrm{I}} A^{\mathrm{I}}-e_{15}^{\mathrm{I}} B^{\mathrm{I}} \\
& D_{2}^{\mathrm{I}}=-e_{15}^{\mathrm{I}} A^{\mathrm{I}}+d_{11}^{\mathrm{I}} B^{\mathrm{I}} \\
& E_{2}^{\mathrm{I}}=B^{\mathrm{I}} \\
& \tau_{23}^{\mathrm{M}}=C_{44}^{\mathrm{M}}\left(\frac{\cos 2 \theta}{r^{2}} A_{-1}^{\mathrm{M}}-A_{1}^{\mathrm{M}}\right)+e_{15}^{\mathrm{M}}\left(\frac{\cos 2 \theta}{r^{2}} B_{-1}^{\mathrm{M}}-B_{1}^{\mathrm{M}}\right) \\
& D_{2}^{\mathrm{M}}=e_{15}^{\mathrm{M}}\left(\frac{\cos 2 \theta}{r^{2}} A_{-1}^{\mathrm{M}}-A_{1}^{\mathrm{M}}\right)-d_{11}^{\mathrm{M}}\left(\frac{\cos 2 \theta}{r^{2}} B_{-1}^{\mathrm{M}}-B_{1}^{\mathrm{M}}\right) \\
& E_{2}^{\mathrm{M}}=-\frac{\cos 2 \theta}{r^{2}} B_{-1}^{\mathrm{M}}+B_{1}^{\mathrm{M}}
\end{aligned}
$$

The expressions of the corresponding quantities for the outer piezoelectric phase can be written by changing superscript $\mathrm{M}$ of the relevant quantities in Eqs. (40)-(42) into C.

The present model and solution are of practical importance. Sections 4 and 5 will focus on demonstrating their application in two aspects of piezoelectric composites.

\section{Stress and electrical field concentrations}

Stress and electrical field concentrations in the microstructures constitute an important topic in design, manufacture and use of piezoelectric composites. Generally it is desirable to alleviate stress and electrical field concentrations for improving mechanical and electrical strength of materials and structures, but sometimes we may need a high electrical field concentration to build a sensitive sensor. The three-phase model can serve as a fiber/interphase layer/matrix model that can be applied to the study of this topic.

\subsection{Example 1: Two-phase piezoelectric cylinder model under a far-field antiplane shear and a far-field inplane electrical field}

This is a special case of the present three-phase model. In fact by letting the material properties in regions $\Omega_{2}$ and $\Omega_{3}$ be the same, i.e. letting

$$
\left(C_{44}^{\mathrm{M}}, e_{15}^{\mathrm{M}}, d_{11}^{\mathrm{M}}\right)=\left(C_{44}^{\mathrm{C}}, e_{15}^{\mathrm{C}}, d_{11}^{\mathrm{C}}\right)
$$

then the present three-phase model degenerates into the two-phase model and the present solution degenerates into

$$
\begin{aligned}
& A^{\mathrm{I}}=2\left\{\left[C_{44}^{\mathrm{M}}\left(d_{11}^{\mathrm{I}}+d_{11}^{\mathrm{M}}\right)+e_{15}^{\mathrm{I}}\left(e_{15}^{\mathrm{I}}+e_{15}^{\mathrm{M}}\right)\right] A_{1}^{\mathrm{M}}+\left(e_{15}^{\mathrm{M}} d_{11}^{\mathrm{I}}-e_{15}^{\mathrm{I}} d_{11}^{\mathrm{M}}\right) B_{1}^{\mathrm{M}}\right\} / \Delta_{1} \\
& B^{\mathrm{I}}=2\left\{\left(C_{44}^{\mathrm{M}} e_{15}^{\mathrm{I}}-C_{44}^{\mathrm{I}} e_{15}^{\mathrm{M}}\right) A_{1}^{\mathrm{M}}+\left[e_{15}^{\mathrm{M}}\left(e_{15}^{\mathrm{M}}+e_{15}^{\mathrm{I}}\right)+d_{11}^{\mathrm{M}}\left(C_{44}^{\mathrm{M}}+C_{44}^{\mathrm{I}}\right)\right] B_{1}^{\mathrm{M}}\right\} / \Delta_{1} \\
& A_{-1}^{\mathrm{M}}=-a^{2}\left\{\left[\left(C_{44}^{\mathrm{M}}-C_{44}^{\mathrm{I}}\right)\left(d_{11}^{\mathrm{I}}+d_{11}^{\mathrm{M}}\right)+\left(e_{15}^{\mathrm{M}}\right)^{2}-\left(e_{15}^{\mathrm{I}}\right)^{2}\right] A_{1}^{\mathrm{M}}+2\left(e_{15}^{\mathrm{M}} d_{11}^{\mathrm{I}}-e_{15}^{\mathrm{I}} d_{11}^{\mathrm{M}}\right) B_{1}^{\mathrm{M}}\right\} / \Delta_{1} \\
& B_{-1}^{\mathrm{M}}=-a^{2}\left\{2\left(C_{44}^{\mathrm{M}} e_{15}^{\mathrm{I}}-C_{44}^{\mathrm{I}} e_{15}^{\mathrm{M}}\right) A_{1}^{\mathrm{M}}+\left[\left(C_{44}^{\mathrm{M}}+C_{44}^{\mathrm{I}}\right)\left(d_{11}^{\mathrm{M}}-d_{11}^{\mathrm{I}}\right)+\left(e_{15}^{\mathrm{M}}\right)^{2}-\left(e_{15}^{\mathrm{I}}\right)^{2}\right] B_{1}^{\mathrm{M}}\right\} / \Delta_{1} \\
& \Delta_{1}=\left(C_{44}^{\mathrm{M}}+C_{44}^{\mathrm{I}}\right)\left(d_{11}^{\mathrm{M}}+d_{11}^{\mathrm{I}}\right)+\left(e_{15}^{\mathrm{M}}+e_{15}^{\mathrm{I}}\right)^{2}
\end{aligned}
$$


where $A_{1}^{\mathrm{M}}$ and $B_{1}^{\mathrm{M}}$ have been given by Eq. (19) or Eq. (21) (noting $A^{\mathrm{M}}=A^{\mathrm{C}}, B^{\mathrm{M}}=B^{\mathrm{C}}$ ), and we obtain the results of Pak (1992). By using the solution the two-phase model, Pak (1992) studied the electroelastic coupling behaviors of the microstructures, which will not be repeated here.

In the next three examples the attention is drawn to stress and electrical field concentrations due to combined action of the inclusion and surrounding interphase layer. To the best of our knowledge, this aspect has not been studied previously.

\subsection{Example 2: Three-phase elastic dielectrical model}

In this case

$$
e_{15}^{\mathrm{I}}=e_{15}^{\mathrm{M}}=e_{15}^{\mathrm{C}}=0
$$

which leads to decoupled stress and electrical fields and the present solution degenerates into

$$
\begin{aligned}
& A^{\mathrm{I}}=-4 b^{2} C_{44}^{\mathrm{M}} \tau_{23}^{0} / \Delta_{2}, \quad B^{\mathrm{I}}=4 b^{2} d_{11}^{\mathrm{M}} D_{2}^{0} / \Delta_{3} \\
& A_{-1}^{\mathrm{M}}=2\left(C_{44}^{\mathrm{M}}-C_{44}^{\mathrm{I}}\right) a^{2} b^{2} \tau_{23}^{0} / \Delta_{2}, \quad B_{-1}^{\mathrm{M}}=-2\left(d_{11}^{\mathrm{M}}-d_{11}^{\mathrm{I}}\right) a^{2} b^{2} D_{2}^{0} / \Delta_{3} \\
& A_{1}^{\mathrm{M}}=-2\left(C_{44}^{\mathrm{M}}+C_{44}^{\mathrm{I}}\right) b^{2} \tau_{23}^{0} / \Delta_{2}, \quad B_{1}^{\mathrm{M}}=2\left(d_{11}^{\mathrm{M}}+d_{11}^{\mathrm{I}}\right) b^{2} D_{2}^{0} / \Delta_{3} \\
& \left\{\begin{array}{l}
A_{-1}^{\mathrm{C}}=2 b^{2}\left[\left(C_{44}^{\mathrm{M}}-C_{44}^{\mathrm{I}}\right) a^{2}+\left(C_{44}^{\mathrm{M}}+C_{44}^{\mathrm{I}}\right) b^{2}\right] \tau_{23}^{0} / \Delta_{2}-b^{2} \tau_{23}^{0} / C_{44}^{\mathrm{C}} \\
B_{-1}^{\mathrm{C}}=-2 b^{2}\left[\left(d_{11}^{\mathrm{M}}-d_{11}^{\mathrm{I}}\right) a^{2}+\left(d_{11}^{\mathrm{M}}+d_{11}^{\mathrm{I}}\right) b^{2}\right] D_{2}^{0} / \Delta_{3}+b^{2} D_{2}^{0} / d_{11}^{\mathrm{C}}
\end{array}\right. \\
& A_{1}^{\mathrm{C}}=-\tau_{23}^{0} / C_{44}^{\mathrm{C}}, \quad B_{1}^{\mathrm{C}}=D_{2}^{0} / d_{11}^{\mathrm{C}}
\end{aligned}
$$

where

$$
\begin{aligned}
& \Delta_{2}=a^{2}\left(C_{44}^{\mathrm{M}}-C_{44}^{\mathrm{C}}\right)\left(C_{44}^{\mathrm{I}}-C_{44}^{\mathrm{M}}\right)+b^{2}\left(C_{44}^{\mathrm{M}}+C_{44}^{\mathrm{C}}\right)\left(C_{44}^{\mathrm{I}}+C_{44}^{\mathrm{M}}\right) \\
& \Delta_{3}=a^{2}\left(d_{11}^{\mathrm{M}}-d_{11}^{\mathrm{C}}\right)\left(d_{11}^{\mathrm{I}}-d_{11}^{\mathrm{M}}\right)+b^{2}\left(d_{11}^{\mathrm{M}}+d_{11}^{\mathrm{C}}\right)\left(d_{11}^{\mathrm{I}}+d_{11}^{\mathrm{M}}\right)
\end{aligned}
$$

By using Eqs. (37)-(42), it is easy to write the explicit expressions of the stress and electrical fields in the inclusion, interphase layer and matrix. From above solution, a surprising analogy is seen between the stress-strain field and electric displacement-electric field. Note that in the latter part of this section, according to the physical interpretation of the three-phase model the symbols of the relevant quantities are changed:

$$
\left(C_{44}^{\mathrm{M}}, C_{44}^{\mathrm{C}}, d_{11}^{\mathrm{M}}, d_{11}^{\mathrm{C}}, \tau_{23}^{\mathrm{M}}, \tau_{23}^{\mathrm{C}},\right) \rightarrow\left(C_{44}^{\mathrm{L}}, C_{44}^{\mathrm{M}}, d_{11}^{\mathrm{L}}, d_{11}^{\mathrm{M}}, \tau_{23}^{\mathrm{L}}, \tau_{23}^{\mathrm{M}},\right)
$$

where the superscripts $\mathrm{L}, \mathrm{M}$ in the bracket on the right-hand side refer to the interphase layer and outer infinite matrix, respectively.

It is seen that for both the two-phase model and three-phase model a constant stress field at infinity induces a constant state of stress within the inclusion. However, the maximum stress concentration within the inclusion for a two-phase model without any interphase layer (or with the interphase of zero thickness) approaches 2, whereas it may be greater than 2 for a three-phase model accounting for interphase layer and it approaches 4 in the limiting case that $C_{44}^{\mathrm{I}} \gg C_{44}^{\mathrm{L}} \gg C_{44}^{\mathrm{M}}$ and $b \gg a$. The latter is more serious than the former. The variations of the inclusion stress with interphase layer stiffness $\left(C_{44}^{\mathrm{L}}\right)$ are plotted in Fig. 2. From damage mechanics, the deterioration of a material can be described by the reduction of the material stiffness. Fig. 2 shows non-monotonic dependence of the inclusion stress on the interphase layer stiffness. When the stiffness of a very stiff interphase layer gradually decreases, the stress in the inclusion first goes up, 


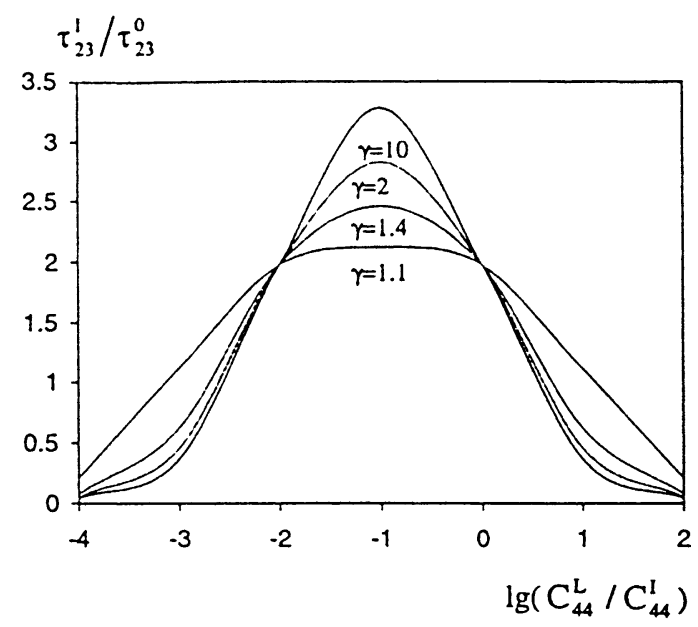

Fig. 2. Variation of inclusion stress with interphase layer stiffness for various interphase layer thickness $\left(C_{44}^{\mathrm{M}} / C_{44}^{\mathrm{I}}=0.01, \gamma=b / a\right)$.

then goes down. In the case of very high or very low interphase layer stiffness, the stress in the inclusion approach zero.

The variation of the stress at point $A$ (see Fig. 1) in the interphase layer is plotted in Fig. 3, which shows that a very high stress concentration can occur in the interphase layer. The stress at point $A$ becomes higher with a thinner and stiffer interphase layer.

The expressions of the electrical field in the three-phase materials are analogous to those of the stress field. The maximum electrical field concentration within the inclusion is 2 for a two-phase model without any interphase layer, whereas it is 4 for a three-phase model accounting for the interphase layer. In the interphase layer a very high electrical field concentration may occur, which may result in dielectrical breakdown. The electrical field within the inclusion is very small when the dielectrical modulus $d_{11}^{\mathrm{I}}$ of the inclusion is much higher than that of surrounding materials. This fact will be used to interpret an interesting phenomenon about the effective piezoelectric modulus of piezoelectric composites in Section 5.

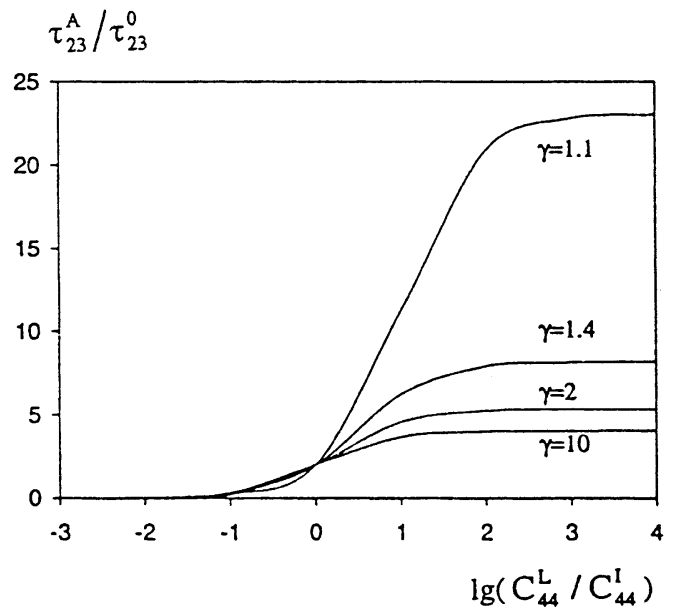

Fig. 3. Variation of stress at point $A$ in interphase layer $\left(C_{44}^{\mathrm{M}} / C_{44}^{\mathrm{I}}=0.01, \gamma=b / a\right)$. 


\subsection{Example 3: Piezoelectric rod with an elastic interphase layer in the elastic matrix}

Piezoelectric composite sensors are often made in this configuration where a piezoelectric rod is embedded in an elastic matrix (usually polymers). Our interest in this case is to maximize the sensitivity of the sensor, i.e. to maximize the electrical field induced in the piezoelectric rod due to the stress field of the surrounding matrix. At the same time we are concerned about the reliability problem such as loss of the sensitivity of the sensor due to interphase layer damage between the sensor and matrix. In this case $e_{15}^{\mathrm{L}}=e_{15}^{\mathrm{M}}=0$. We can also take approximately $d_{11}^{\mathrm{L}}=d_{11}^{\mathrm{M}}=0$ (the reason will be given later, referring to Fig. 6), which will considerably simplify our manipulation. By using the present solution, the electrical field inside the piezoelectric $\operatorname{rod}\left(C_{44}^{\mathrm{I}}, e_{15}^{\mathrm{I}}, d_{11}^{\mathrm{I}}\right)$ with the elastic interphase layer $\left(C_{44}^{\mathrm{L}}\right)$ in the elastic matrix $\left(C_{44}^{\mathrm{M}}\right)$ is

$$
E_{2}^{\mathrm{I}}=\frac{-4 C_{44}^{\mathrm{L}} e_{15}^{\mathrm{I}} b^{2} \tau_{23}^{0}}{\left(C_{44}^{\mathrm{L}}-C_{44}^{\mathrm{M}}\right)\left[\left(C_{44}^{\mathrm{I}}-C_{44}^{\mathrm{L}}\right) d_{11}^{\mathrm{I}}+\left(e_{15}^{\mathrm{I}}\right)^{2}\right] a^{2}+\left(C_{44}^{\mathrm{L}}+C_{44}^{\mathrm{M}}\right)\left[\left(C_{44}^{\mathrm{I}}+C_{44}^{\mathrm{L}}\right) d_{11}^{\mathrm{I}}+\left(e_{15}^{\mathrm{I}}\right)^{2}\right] b^{2}}
$$

This expression shows non-monotonic dependence of the induced electric field within the piezoelectric rod on the piezoelectric modulus $e_{15}^{\mathrm{I}}$ of the piezoelectric rod as well as the shear modulus $C_{44}^{\mathrm{L}}$ of the interphase layer, which is plotted in Figs. 4 and 5, respectively, where $C_{44}^{\mathrm{I}}=31.4 \mathrm{GPa}, e_{15}^{\mathrm{I}}=10.4 \mathrm{C} / \mathrm{m}^{2}$ (only for Fig. $5), d_{11}^{\mathrm{I}}=7.95 \mathrm{nC}^{2} / \mathrm{N} \mathrm{m}^{2}$. Fig. 4 indicates that maximizing the piezoelectric constant alone will not necessarily maximize the sensitivity of the sensor (piezoelectric rod); it has to be matched with the rest of the material parameters. Fig. 5 indicates that the mechanical damage (decrease of the stiffness) of the interphase layer will not necessarily result in reduction of the output of the sensor; in some cases a slight damage may even result in the increase of the output. Of course, very serious interphase layer damage will certainly lead to loss of output of the sensor. The two interesting phenomena may be useful in the design and integrity estimation of piezoelectric composites.

Let $C_{44}^{\mathrm{L}}=C_{44}^{\mathrm{M}}$, Eq. (58) degenerate into

$$
E_{2}^{\mathrm{I}}=-2 e_{15}^{\mathrm{I}} \tau_{23}^{0} /\left[\left(C_{44}^{\mathrm{M}}+C_{44}^{\mathrm{I}}\right) d_{11}^{\mathrm{I}}+\left(e_{15}^{\mathrm{I}}\right)^{2}\right]
$$

which coincides with the result of Pak (1992).

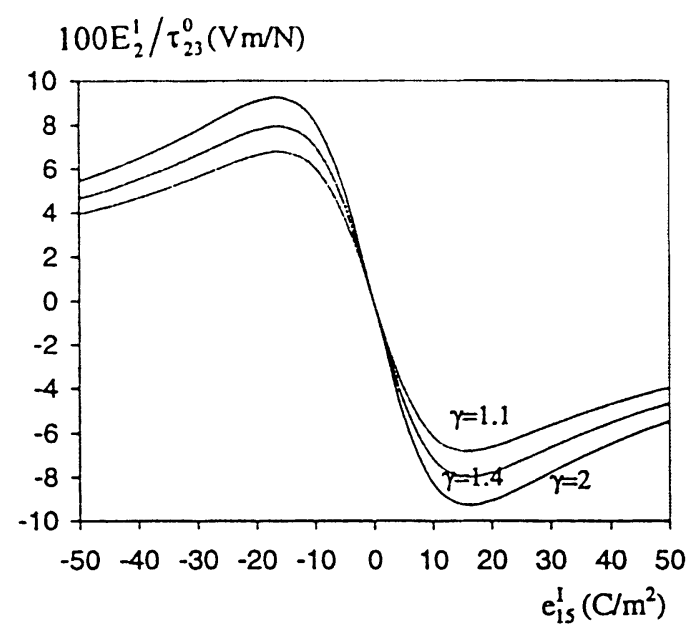

Fig. 4. Non-monotonic dependence of inclusion electrical field on inclusion piezoelectric modulus $\left(C_{44}^{\mathrm{M}} / C_{44}^{\mathrm{I}}=0.01, C_{44}^{\mathrm{L}} / C_{44}^{\mathrm{I}}=0.1\right.$, $\gamma=b / a)$. 


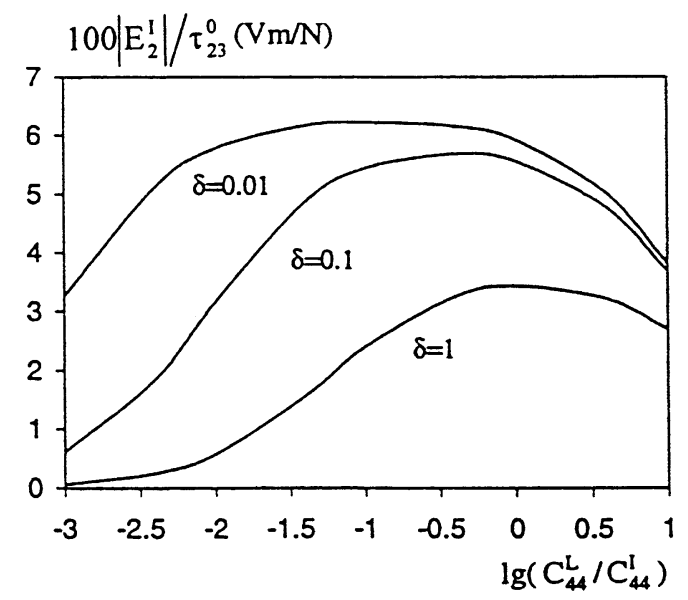

Fig. 5. Non-monotonic dependence of inclusion electrical field on inclusion piezoelectric modulus $\left(\delta=C_{44}^{\mathrm{M}} / C_{44}^{\mathrm{I}}, b / a=1.1\right)$.

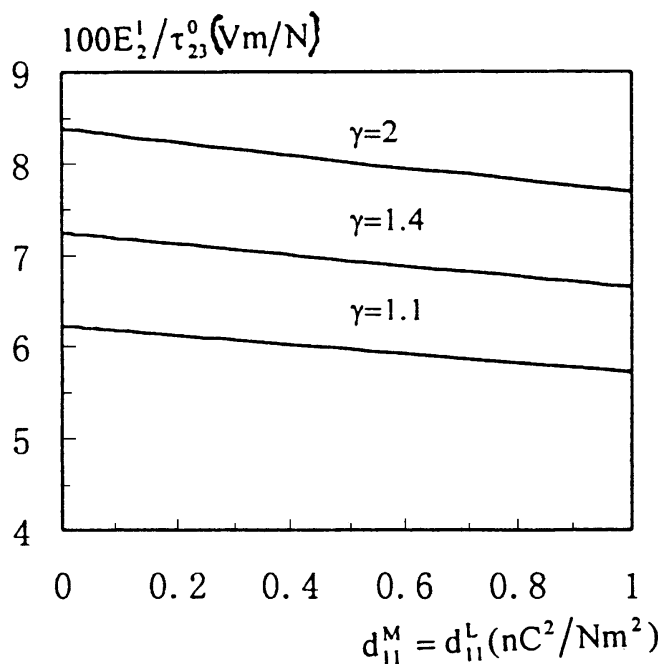

Fig. 6. Influence of the dielectric constants in the elastic interphase layer and matrix $\left(C_{44}^{\mathrm{M}}: C_{44}^{\mathrm{L}}: C_{44}^{\mathrm{I}}=1: 10: 100, e_{15}^{\mathrm{M}}=e_{15}^{\mathrm{L}}=0, \gamma=b / a\right)$.

Finally, we examine the influence of the dielectric constants $\left(d_{11}^{\mathrm{L}}, d_{11}^{\mathrm{M}}\right)$ in the elastic interphase layer and matrix. Because $d_{11}^{\mathrm{L}}$ and $d_{11}^{\mathrm{M}}$ are very small (for example, $d_{11}=0.037 \mathrm{nC}^{2} / \mathrm{N} \mathrm{m}^{2}$ for the epoxy, $d_{11}=0.0797$ $\mathrm{nC}^{2} / \mathrm{N} \mathrm{m}^{2}$ for the polymer), their influence is negligible. To illustrate this, the variations of the rod electric field with $d_{11}^{\mathrm{M}}$ (taking $d_{11}^{\mathrm{L}}=d_{11}^{\mathrm{M}}$ ) are plotted in Fig. 6, where $C_{44}^{\mathrm{I}}=31.4 \mathrm{GPa}, e_{15}^{\mathrm{I}}=-10.4 \mathrm{C} / \mathrm{m}^{2}, d_{11}^{\mathrm{I}}=7.95$ $\mathrm{nC}^{2} / \mathrm{N} \mathrm{m}^{2}, C_{44}^{\mathrm{M}}: C_{44}^{\mathrm{L}}: C_{44}^{\mathrm{I}}=1: 10: 100$.

\subsection{Example 4. Piezoelectric rod with a piezoelectric interphase layer in the piezoelectric matrix}

This is a most general case and in computation the electroelastic moduli of the piezoelectric rod is taken as $C_{44}^{\mathrm{I}}=35.3 \mathrm{GPa}, e_{15}^{\mathrm{I}}=10.0 \mathrm{C} / \mathrm{m}^{2}, d_{11}=15.1 \mathrm{nC}^{2} / \mathrm{N} \mathrm{m}^{2}$. In the case of vanishing stress state at infinity, the inclusion electrical field concentrations are plotted in Fig. 7 as a function of the ratio $e_{15}^{\mathrm{M}} / e_{15}^{\mathrm{I}}$ of the pi- 


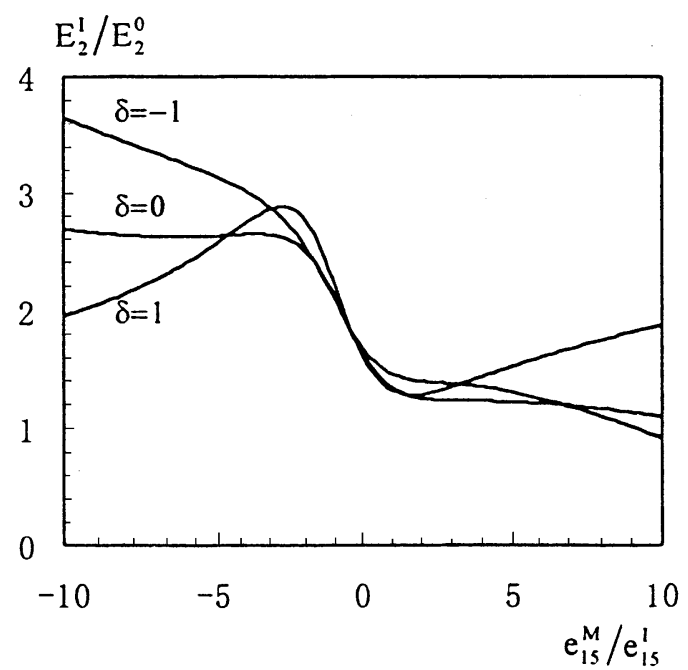

Fig. 7. Electric field concentrations as a function of $e_{15}^{\mathrm{M}} / e_{15}^{\mathrm{I}}\left(C_{44}^{\mathrm{M}}: C_{44}^{\mathrm{L}}: C_{44}^{\mathrm{I}}=1: 5: 10, d_{11}^{\mathrm{M}}: d_{11}^{\mathrm{L}}: d_{11}^{\mathrm{I}}=1: 5: 10, b / a=1.1, \delta=e_{15}^{\mathrm{L}} / e_{15}^{\mathrm{I}}\right)$.

ezoelectric modulus to that of the inclusion for various $e_{15}^{\mathrm{L}} / e_{15}^{\mathrm{I}}$ and in Fig. 8 as a function of $e_{15}^{\mathrm{L}} / e_{15}^{\mathrm{I}}$ for various $e_{15}^{\mathrm{M}} / e_{15}^{\mathrm{I}}$, where $C_{44}^{\mathrm{M}}: C_{44}^{\mathrm{L}}: C_{44}^{\mathrm{I}}=1: 5: 10, d_{11}^{\mathrm{M}}: d_{11}^{\mathrm{L}}: d_{11}^{\mathrm{I}}=1: 5: 10, b / a=1.1$. It is seen that the curves vary monotonically or non-monotonically depending on the alignment of these piezoelectric moduli. Now we consider the coupling of the electric field and stress state at infinity. In the case of $C_{44}^{\mathrm{M}}=C_{44}^{\mathrm{L}}=C_{44}^{\mathrm{I}}$, the variations of the inclusion electric field with the piezoelectric modulus $e_{15}^{\mathrm{L}} / e_{15}^{\mathrm{I}}$ of the interphase layer for various stress states at infinity are plotted in Fig. 9. It is seen that the stress field at infinity may take variation of the rod electric field sharper. We further consider the influence of different alignments of the electrostatic moduli of the three phase materials. The electric and stress fields in the piezoelectric rod as the functions of the piezoelectric modulus of the matrix are plotted in Figs. 10 and 11, respectively, where $C_{44}^{\mathrm{M}}: C_{44}^{\mathrm{L}}: C_{44}^{\mathrm{I}}=1: 5: 10, d_{11}^{\mathrm{M}}: d_{11}^{\mathrm{L}}: d_{11}^{\mathrm{I}}=1: 5: 10, e^{\mathrm{L}}=0.5 e^{\mathrm{I}}$ and $b / a=10$. In such cases we may observe very high concentrations of electric and stress fields.

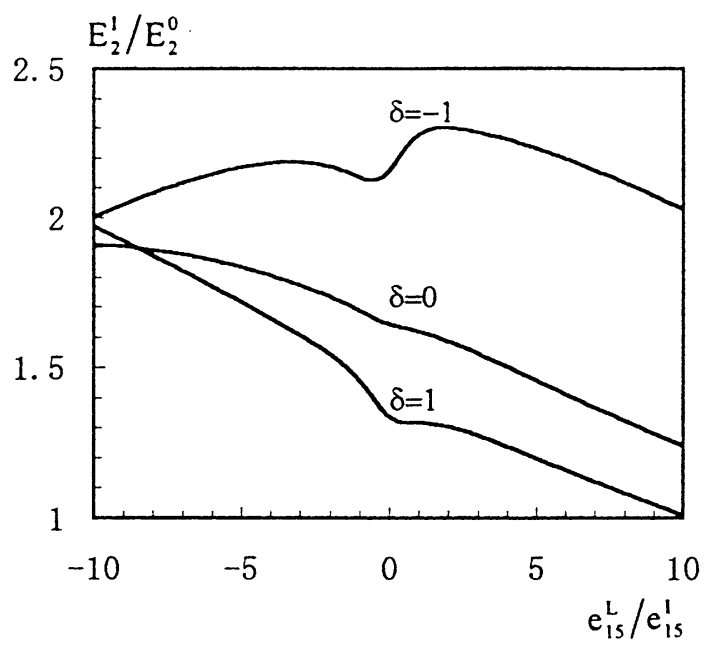

Fig. 8. Electric field concentrations as a function of $e_{15}^{\mathrm{L}} / e_{15}^{\mathrm{I}}\left(C_{44}^{\mathrm{M}}: C_{44}^{\mathrm{L}}: C_{44}^{\mathrm{I}}=1: 5: 10, d_{11}^{\mathrm{M}}: d_{11}^{\mathrm{L}}: d_{11}^{\mathrm{I}}=1: 5: 10, b / a=1.1, \delta=e_{15}^{\mathrm{M}} / e_{15}^{\mathrm{I}}\right)$. 


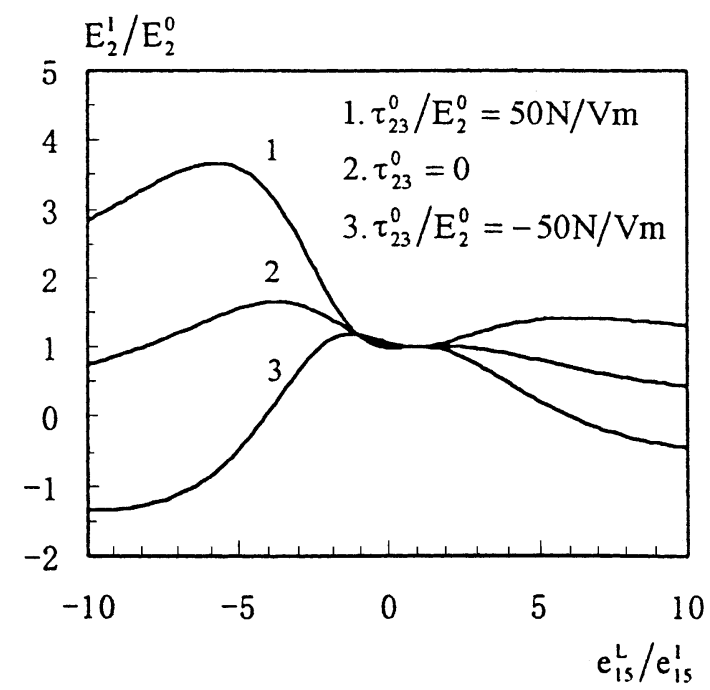

Fig. 9. Electric field concentrations as a function of $e_{15}^{\mathrm{L}} / e_{15}^{\mathrm{I}}$ for various stress states at infinity $\left(C_{44}^{\mathrm{M}}=C_{44}^{\mathrm{L}}=C_{44}^{\mathrm{I}}, d_{11}^{\mathrm{M}}=d_{11}^{\mathrm{L}}=d_{11}^{\mathrm{I}}\right.$, $\left.e_{15}^{\mathrm{M}}=e_{15}^{\mathrm{I}}, b / a=10\right)$.

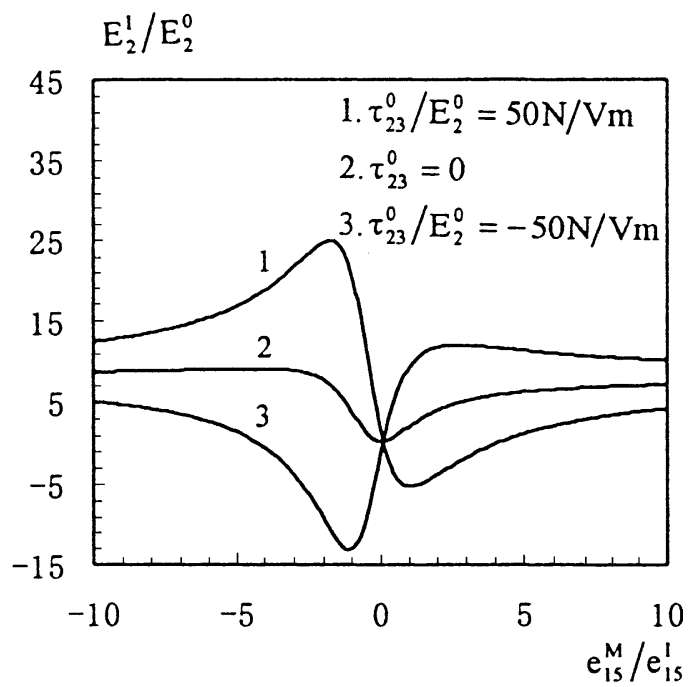

Fig. 10. Electric field concentrations as a function of $e_{15}^{\mathrm{M}} / e_{15}^{\mathrm{I}}$ for various stress states at infinity $\left(C_{44}^{\mathrm{M}}: C_{44}^{\mathrm{L}}: C_{44}^{\mathrm{I}}=1: 5: 10, d_{11}^{\mathrm{M}}: d_{11}^{\mathrm{L}}: d_{11}^{\mathrm{I}}=\right.$ $\left.1: 5: 10, e_{15}^{\mathrm{L}}=0.5 e_{15}^{\mathrm{I}}, b / a=10\right)$.

\section{Prediction of effective electroelastic moduli}

To estimate the effective elastic properties of traditional (non-piezoelectric) composites, much of the theoretical study has been focused on the development of micromechanics model. The dilute, self-consistent, Mori-Tanaka (Mori and Tanaka, 1973) and differential schemes are the micromechanics theories that have received considerable attention, and they have been extended to consider the coupled electroelastic properties of piezoelectric composites (Dunn and Taya, 1993). The generalized self-consistent scheme is 


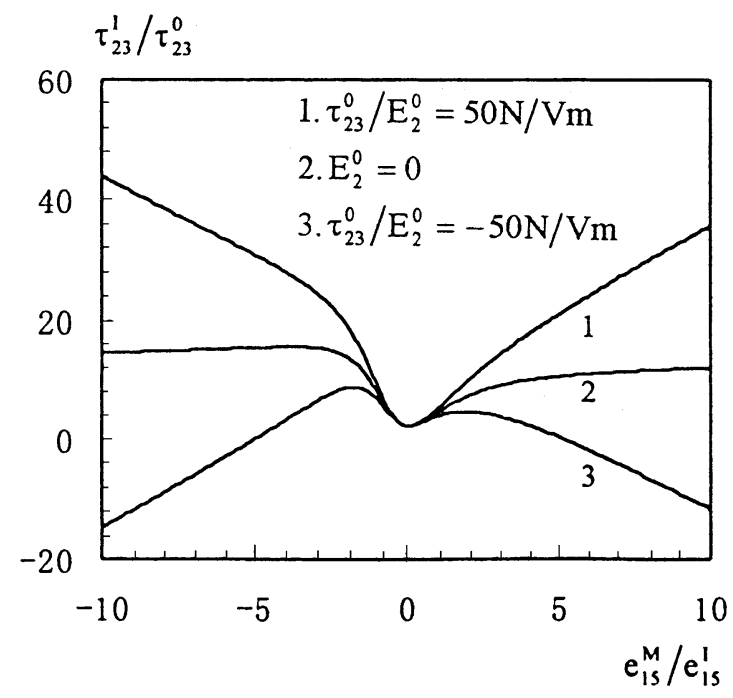

Fig. 11. Stress field concentrations as a function of $e_{15}^{\mathrm{M}} / e_{15}^{\mathrm{I}}$ for various electric field at infinity $\left(C_{44}^{\mathrm{M}}: C_{44}^{\mathrm{L}}: C_{44}^{\mathrm{I}}=1: 5: 10, d_{11}^{\mathrm{M}}: d_{11}^{\mathrm{L}}: d_{11}^{\mathrm{I}}=1: 5: 10\right.$, $\left.e_{15}^{\mathrm{L}}=0.5 e_{15}^{\mathrm{I}}, b / a=10\right)$.

another sophisticated micromechanics theory, which has been applied with great success to a number of problems in predicting the effective elastic properties of composites (Christensen and Lo, 1979; Luo and Weng, 1987, 1989; Huang et al., 1994; Huang and Hu, 1995; Jiang and Cheung, 1998). However it appears that this micromechanics theory has not been further applied to predict the effective electroelastic moduli of piezoelectric composites. The present three-phase model can serve as a fiber/matrix/composite model, in terms of which a generalized self-consistent approach will be developed for predicting the effective electroelastic moduli of piezoelectric composites.

As is well known, the dilute approximation is a simple micromechanics approach, where the essential assumption is that the interaction among the reinforced phase in matrix-based composites can be ignored. The essential assumption employed in the self-consistent theory is that the reinforced phase is embedded in the effective (composite) medium of as yet unknown moduli, which appears to overestimate the interaction among the reinforced phase. The generalized self-consistent theory is an improvement on the dilute and self-consistent theories. The essential assumption of the generalized self-consistent theory is that a fiber (or inclusion, in $\Omega_{1}$ in Fig. 1) is embedded in an annular matrix (in $\Omega_{2}$ ) which, in turn, is embedded in the effective (composite) medium (in $\Omega_{3}$ ). The fiber and surrounding matrix make up a representative unit cell, the size of which is chosen so as to preserve the fiber volume fraction $\lambda$ of the composite, that is

$$
\lambda=\left(\frac{a}{b}\right)^{2}
$$

General expression for the effective moduli of two-phase perfectly bonded piezoelectric composites can be derived by considering the volume average of the piezoelectric field variables (see for example Dunn and Taya, 1993):

$$
\begin{aligned}
& \{\bar{\Sigma}\}^{\mathrm{C}}=\lambda\{\bar{\Sigma}\}^{\mathrm{I}}+(1-\lambda)\{\bar{\Sigma}\}^{\mathrm{M}} \\
& \{\overline{\mathbf{Z}}\}^{\mathrm{C}}=\lambda\{\overline{\mathbf{Z}}\}^{\mathrm{I}}+(1-\lambda)\{\overline{\mathbf{Z}}\}^{\mathrm{M}}
\end{aligned}
$$


where $\{\Sigma\}$ is the generalized stress vector, which consists of stresses and electrical displacement components; $\{\overline{\mathbf{Z}}\}$ is the generalized strain vector, which consists of strains and electrical field components; an overbar denotes the volume average of a quantity.

Consider the two-phase composite being subjected to homogeneous elastic displacement-electrical potential boundary conditions $\left\{\mathbf{Z}^{0}\right\}$ (far-field conditions). By homogeneous boundary conditions it is meant that when they are applied to a homogeneous solid they result in homogeneous fields. Evaluation of the volume averaged piezoelectric fields results yields the effective electroelastic modulus matrix $[\mathbf{C}]$ :

$$
\{\bar{\Sigma}\}=[\mathbf{C}]\{\overline{\mathbf{Z}}\}
$$

For the problem of antiplane strain and inplane electrical field under consideration, the vectors and matrix in Eq. (63) are

$$
\begin{aligned}
& \{\bar{\Sigma}\}=\left[\bar{\tau}_{23}, \overline{\boldsymbol{D}}_{2}\right]^{\mathrm{T}}, \quad\{\overline{\mathbf{Z}}\}=\left[\bar{\gamma}_{23}, \overline{\boldsymbol{E}}_{2}\right]^{\mathrm{T}} \\
& {[\mathbf{C}]=\left[\begin{array}{cc}
C_{44} & -e_{15} \\
e_{15} & d_{11}
\end{array}\right]}
\end{aligned}
$$

Noting that the perturbation of the strain and electrical field vanishes when integrated over the domain of the entire composite, $\{\overline{\mathbf{Z}}\}$ can be obtained as

$$
\{\overline{\mathbf{Z}}\}=\left\{\mathbf{Z}^{0}\right\}
$$

This is a generalization of the average strain theorem of elasticity (see for example Aboudi, 1991). Similarly, we can also obtain

$$
\{\bar{\Sigma}\}=\left\{\Sigma^{0}\right\}
$$

where $\left\{\Sigma^{0}\right\}$ is the far-field generalized stress. According to the generalized self-consistent theory, the average stress and strain in a representative unit cell are identical to those in the entire composite. It should be pointed out that in a representative unit cell Eq. (66) or Eq. (67) can replace Eq. (63) to predict the effective electroelastic moduli. In fact the three approaches provided by the three equations are equivalent and a proof is given in the Appendix A. The fact shows also the superiority of the generalized self-consistent model from another angle.

For the problem under consideration, Eq. (66) can be rewritten as

$$
\begin{aligned}
& \iint_{\Omega_{1}} \gamma_{23}^{\mathrm{I}} \mathrm{d} \Omega+\iint_{\Omega_{2}} \gamma_{23}^{\mathrm{M}} \mathrm{d} \Omega=\pi b^{2} \gamma_{23}^{0} \\
& \iint_{\Omega_{1}} E_{2}^{\mathrm{I}} \mathrm{d} \Omega+\iint_{\Omega_{2}} E_{2}^{\mathrm{M}} \mathrm{d} \Omega=\pi b^{2} E_{2}^{0}
\end{aligned}
$$

Eqs. (68) and (69) can be interpreted as a equivalence of the strain and electrical fields between two different views of the piezoelectric composite: one regards the piezoelectric composite as an overall effective piezoelectric medium, and the other goes into the details of the individual phase. Letting

$$
\left\{\mathbf{Z}^{0}\right\}=\left[\gamma_{23}^{0}, 0\right]^{\mathrm{T}}
$$

and using the exact solution for the three-phase model, Eqs. (68) and (69) can be reduced as

$$
\begin{aligned}
& 2\left[a^{2}\left(1-P_{1}\right)+b^{2} P_{1}\right]\left(C_{44}^{\mathrm{C}} Q_{4}-e_{15}^{\mathrm{C}} Q_{2}\right)-2\left(b^{2}-a^{2}\right) P_{2}\left(C_{44}^{\mathrm{C}} Q_{3}-e_{15}^{\mathrm{C}} Q_{1}\right)=Q_{1} Q_{4}-Q_{2} Q_{3} \\
& -\left(b^{2}-a^{2}\right) P_{3}\left(C_{44}^{\mathrm{C}} Q_{4}-e_{15}^{\mathrm{C}} Q_{2}\right)+\left[a^{2}\left(1-P_{4}\right)+b^{2} P_{4}\right]\left(C_{44}^{\mathrm{C}} Q_{3}-e_{15}^{\mathrm{C}} Q_{1}\right)=0
\end{aligned}
$$


Letting

$$
\left\{\mathbf{Z}^{0}\right\}=\left[0, E_{2}^{0}\right]^{\mathrm{T}}
$$

Eqs. (68) and (69) can be reduced as

$$
\begin{aligned}
& -\left[a^{2}\left(1-P_{1}\right)+b^{2} P_{1}\right]\left(e_{15}^{\mathrm{C}} Q_{4}+d_{11}^{\mathrm{C}} Q_{2}\right)+\left(b^{2}-a^{2}\right) P_{2}\left(e_{15}^{\mathrm{C}} Q_{3}+d_{11}^{\mathrm{C}} Q_{1}\right)=0 \\
& 2\left(b^{2}-a^{2}\right) P_{3}\left(e_{15}^{\mathrm{C}} Q_{4}+d_{11}^{\mathrm{C}} Q_{2}\right)-2\left[a^{2}\left(1-P_{4}\right)+b^{2} P_{4}\right]\left(e_{15}^{\mathrm{C}} Q_{3}+d_{11}^{\mathrm{C}} Q_{1}\right)=Q_{1} Q_{4}-Q_{2} Q_{3}
\end{aligned}
$$

It can be seen that there are only three independent equations in the four Eqs. (70)-(73), in terms of which, three electroelastic moduli $C_{44}^{\mathrm{C}}, e_{15}^{\mathrm{C}}$ and $d_{11}^{\mathrm{C}}$ of piezoelectric composites can be determined.

\subsection{Example 1: Both the fiber and matrix are the elastic dielectric materials}

In this case

$$
e_{15}^{\mathrm{I}}=e_{15}^{\mathrm{M}}=0
$$

Solving Eqs. (70)-(73), we obtain

$$
\begin{aligned}
& e_{15}^{\mathrm{C}}=0 \\
& C_{44}^{\mathrm{C}}=\frac{a^{2}\left(C_{44}^{\mathrm{I}}-C_{44}^{\mathrm{M}}\right)+b^{2}\left(C_{44}^{\mathrm{I}}+C_{44}^{\mathrm{M}}\right)}{a^{2}\left(C_{44}^{\mathrm{M}}-C_{44}^{\mathrm{I}}\right)+b^{2}\left(C_{44}^{\mathrm{M}}+C_{44}^{\mathrm{I}}\right)} C_{44}^{\mathrm{M}} \\
& d_{11}^{\mathrm{C}}=\frac{a^{2}\left(d_{11}^{\mathrm{I}}-d_{11}^{\mathrm{M}}\right)+b^{2}\left(d_{11}^{\mathrm{I}}+d_{11}^{\mathrm{M}}\right)}{a^{2}\left(d_{11}^{\mathrm{M}}-d_{11}^{\mathrm{I}}\right)+b^{2}\left(d_{11}^{\mathrm{M}}+d_{11}^{\mathrm{I}}\right)} d_{11}^{\mathrm{M}}
\end{aligned}
$$

where formula (76) is in agreement with the classical formula predicting the effective longitudinal shear modulus of a fiber reinforced composite (Hashin and Rosen, 1964; Whitney and Riley, 1966).

\subsection{Example 2: PZT-7A fiber reinforced epoxy composite}

Here $C_{44}^{\mathrm{I}}=25.4 \mathrm{GPa}, e_{15}^{\mathrm{I}}=9.2 \mathrm{C} / \mathrm{m}^{2}, d_{11}^{\mathrm{I}}=4.071 \mathrm{nC}^{2} / \mathrm{Nm}^{2}$ for PZT-7A fiber, and $C_{44}^{\mathrm{M}}=1.8 \mathrm{GPa}$, $e_{15}^{\mathrm{M}}=0, d_{11}^{\mathrm{M}}=0.03717 \mathrm{nC}^{2} / \mathrm{N} \mathrm{m}^{2}$ for the epoxy matrix.

The effective electroelastic moduli $C_{44}^{\mathrm{C}}, e_{15}^{\mathrm{C}}$ and $d_{11}^{\mathrm{C}}$ of this piezoelectric composite for various fiber volume fraction are listed in Table 1.

\subsection{Example 3: Porous PZT-5 ceramic}

Two cases are considered: (1) with empty cylindrical voids, (2) the voids being filled with polymer. The electroelastic moduli of the constituent materials are $C_{44}^{\mathrm{I}}=0.64 \mathrm{GPa}, e_{15}^{\mathrm{I}}=0, d_{11}^{\mathrm{I}}=0.0797 \mathrm{nC}^{2} / \mathrm{N} \mathrm{m}^{2}$ for polymer, and $C_{44}^{\mathrm{M}}=21.1 \mathrm{GPa}, e_{15}^{\mathrm{M}}=12.3 \mathrm{C} / \mathrm{m}^{2}, d_{11}^{\mathrm{M}}=8.107 \mathrm{nC}^{2} / \mathrm{N} \mathrm{m}^{2}$ for PZT-5 ceramic.

The effective electroelastic moduli $C_{44}^{\mathrm{C}}, e_{15}^{\mathrm{C}}$ and $d_{11}^{\mathrm{C}}$ of the porous PZT-5 ceramic for the two cases are listed in Tables 2 and 3 respectively.

From the numerical examples, it is seen that the Eqs. (70)-(73) are very convenient and efficient in determining the relevant effective electroelastic moduli of piezoelectric composites. They are well suited for extreme types of inclusions (from voids to rigid inclusions) as well as the full range of inclusion volume fraction variation from 0 to 1 (fully packed). 
Table 1

The effective electrostatic moduli of a PZT-7A fibre reinforced epoxy composite for various fiber volume fractions

\begin{tabular}{lllllllll}
\hline & $\lambda=0.2$ & $\lambda=0.4$ & $\lambda=0.5$ & $\lambda=0.6$ & $\lambda=0.7$ & $\lambda=0.8$ & $\lambda=0.9$ & $\lambda=1$ \\
\hline$C_{44}^{\mathrm{C}}(\mathrm{GPa})$ & 2.6167 & 3.9117 & 4.8922 & 6.2770 & 8.3795 & 11.938 & 19.114 & 25.40 \\
$e_{15}^{\mathrm{C}}\left(\mathrm{C} / \mathrm{m}^{2}\right)$ & 0.0038 & 0.0132 & 0.0231 & 0.0416 & 0.0808 & 0.1818 & 0.5999 & 9.200 \\
$d_{11}^{\mathrm{C}}\left(\mathrm{nC}^{2} / \mathrm{N} \mathrm{m}^{2}\right)$ & 0.0555 & 0.0859 & 0.1099 & 0.1456 & 0.2042 & 0.3174 & 0.6260 & 4.071 \\
\hline
\end{tabular}

Table 2

The effective electroelastic moduli of a cylindrically porous PZT-5 ceramic for various porosity volume fractions

\begin{tabular}{lcccccccc}
\hline & $\lambda=0$ & $\lambda=0.1$ & $\lambda=0.2$ & $\lambda=0.3$ & $\lambda=0.5$ & $\lambda=0.6$ & $\lambda=0.8$ & $\lambda=0.9$ \\
\hline$C_{44}^{\mathrm{C}}(\mathrm{GPa})$ & 21.100 & 17.264 & 14.067 & 11.362 & 7.0333 & 5.2750 & 2.3445 & 1.1105 \\
$e_{15}^{\mathrm{C}}\left(\mathrm{C} / \mathrm{m}^{2}\right)$ & 12.300 & 10.064 & 8.2000 & 6.6231 & 4.1000 & 3.0750 & 1.3667 & 0.6474 \\
$d_{11}^{\mathrm{C}}\left(\mathrm{nC}^{2} / \mathrm{N} \mathrm{m}^{2}\right)$ & 8.1070 & 6.6359 & 5.4096 & 4.3716 & 2.7102 & 2.0350 & 0.9095 & 0.4355 \\
\hline
\end{tabular}

Table 3

The effective electroelastic moduli of a PZT-5 ceramic with cylindrical voids filled with polymer for various porosity volume fractions

\begin{tabular}{lcccccccc}
\hline & $\lambda=0$ & $\lambda=0.1$ & $\lambda=0.2$ & $\lambda=0.3$ & $\lambda=0.5$ & $\lambda=0.6$ & $\lambda=0.8$ & $\lambda=0.9$ \\
\hline$C_{44}^{\mathrm{C}}(\mathrm{GPa})$ & 21.000 & 17.473 & 14.419 & 11.812 & 7.5992 & 5.8726 & 2.9754 & 1.7482 \\
$e_{15}^{\mathrm{C}}\left(\mathrm{C} / \mathrm{m}^{2}\right)$ & 12.300 & 10.064 & 8.2007 & 6.6238 & 4.1006 & 3.0755 & 1.3669 & 0.6475 \\
$d_{11}^{\mathrm{C}}\left(\mathrm{nC}^{2} / \mathrm{N} \mathrm{m}^{2}\right)$ & 8.1070 & 6.6592 & 5.4488 & 4.4217 & 2.7731 & 2.1014 & 0.9794 & 0.5061 \\
\hline
\end{tabular}

It is interesting to observe from Table 1 that the effective piezoelectric modulus of the piezoelectric composite is very low. When the volume fraction of the PZT-7A fiber with $e_{15}^{\mathrm{I}}=9.2 \mathrm{C} / \mathrm{m}^{2}$ goes up to 0.9 , the effective piezoelectric modulus of the piezoelectric composite is still at a low value of $e_{15}^{\mathrm{C}}=0.5999 \mathrm{C} / \mathrm{m}^{2}$. An in-depth investigation indicates that the reason for that is the non-homogeneity of the electrical field in the microstructure of piezoelectric composites. The piezoelectric effect of the PZT-7A fiber reinforced epoxy composite stems from the PZT-7A fibers. Because the dielectrical modulus of the PZT-7A fiber is much higher than the epoxy matrix, the electrical field in the PZT-7A fiber (induced by a far-field electrical field) is very weak (refer to the preceding section), and so the piezoelectric modulus of the PZT-7A fiber reinforced epoxy composite is small. Keeping the remaining electroelastic moduli (except $d_{11}^{\mathrm{M}}$ ) of the constituent materials in Example 1 unchanged, it can be seen that the effective piezoelectric modulus of the piezoelectric composite increases with the increase of dielectrical modulus of the matrix (see Table 4).

Finally, it should be pointed out that, to the best of the authors' knowledge, predictions for the three effective electroelastic moduli $C_{44}^{\mathrm{C}}, e_{15}^{\mathrm{C}}$ and $d_{11}^{\mathrm{C}}$ of piezoelectric composites have not been reported. Although the present algebraic equations for predicting effective electroelastic moduli have been well verified in the special case of mechanical and electrical decoupling, further verification of the general case of mechanical and electrical coupling will need to be carried out.

Table 4

The effective piezoelectric modulus varies with the matrix dielectrical modulus

\begin{tabular}{llllll}
\hline$d_{11}^{\mathrm{M}}\left(\mathrm{nC}^{2} / \mathrm{N} \mathrm{m}^{2}\right)$ & 0.0372 & 0.0471 & 0.0814 & 0.2036 & 0.4071 \\
$e_{15}^{\mathrm{C}}\left({\left.\mathrm{C} / \mathrm{m}^{2}\right)}^{2}\right.$ & 0.1838 & 0.2003 & 0.3792 & 0.8167 & 1.3270 \\
\hline
\end{tabular}

Note: The volume fraction of the fiber $\lambda=0.8$; the remaining electroelastic moduli except $d_{11}^{\mathrm{M}}$ of the constituents are the same as those in Example 1. 


\section{Conclusion}

(1) A three-phase cylindrically concentrated piezoelectric solid micromechanics model is developed, and an exact solution for this model under a far-field antiplane shear and a far-field inplane electrical field is obtained by using complex electroelastic potentials integrated with the Laurent expansion technique. Several classical models and solutions can be obtained as the degenerated cases of the present model and solution.

(2) The three-phase model can serve as a fiber/interphase layer/matrix model, which is very useful in understanding the mechanical and electrical coupling behavior of piezoelectric composites. A number of interesting coupled electroelastic phenomena is revealed. It is found that in the limiting case the maximum stress and electrical field concentrations in the piezoelectric fiber approach 4 for the three-phase model that incorporates the interphase layer, whereas they approach 2 for the two-phase model without the interphase layer. The stress and electrical field concentrations can go up to a very high level in the interphase layer. The electrical field induced by the mechanical load in the piezoelectric fiber shows non-monotonic dependence on the piezoelectric modulus of the fiber and the shear modulus of the interphase layer. The effects may contribute to maximizing the sensitivity of the sensor and estimating structural integrity.

(3) The three-phase model can serve as a fiber/matrix/composite micromechanics model, in terms of which a generalized self-consistent approach for predicting the effective electroelastic moduli of piezoelectric composites is developed. The generalized self-consistent approach is an improvement on the dilute and self-consistent approaches, and it is well suited for extreme types of inclusions (from voids to rigid inclusions) as well as the full range of inclusion volume fraction variation. By using the exact solution obtained, a set of simple and explicit algebraic equations for determining the relevant effective electroelastic moduli of piezoelectric composites is derived. Numerical examples are given and discussed in detail.

\section{Acknowledgements}

The work is supported by the Hong Kong Research Grants Council, the National Natural Science Foundation of China and the Aviation Science Foundation of China.

\section{Appendix A. A proof that the three approaches are equivalent for predicting the effective electroelastic moduli}

(1) The solution in matrix form for three-phase model

For brevity the relevant quantities in Eqs. (1)-(10) are put in matrix form

$$
\begin{aligned}
& \mathbf{Z}=\left\{\begin{array}{c}
\gamma_{23} \\
E_{2}
\end{array}\right\}, \quad \Sigma=\left\{\begin{array}{c}
\tau_{23} \\
D_{2}
\end{array}\right\} \\
& \mathbf{U}=\left\{\begin{array}{c}
w \\
-\varphi
\end{array}\right\}, \quad \mathbf{T}=\left\{\begin{array}{c}
T_{\tau} \\
T_{D}
\end{array}\right\} \\
& \Sigma=\mathbf{C Z}, \quad \mathbf{C}=\left[\begin{array}{cc}
C_{44} & -e_{15} \\
e_{15} & d_{11}
\end{array}\right]
\end{aligned}
$$

Referring to Eqs. (14)-(16), the constants to be determined are also put in matrix form:

$$
\mathbf{A}^{\mathrm{i}}=\left\{\begin{array}{c}
A^{\mathrm{i}} \\
-B^{\mathrm{i}}
\end{array}\right\}, \quad \boldsymbol{\Phi}^{\mathrm{i}}(\mathbf{z})=\left\{\begin{array}{c}
\Phi(z) \\
\Psi(z)
\end{array}\right\}
$$


where the superscripts $\mathrm{i}=\mathrm{I}, \mathrm{M}, \mathrm{C}$ correspond to the fiber, matrix and equivalent composite medium, respectively.

From the far-field condition (17), we obtain

$$
\Sigma^{0}=\left\{\begin{array}{c}
\tau_{23}^{0} \\
D_{2}^{0}
\end{array}\right\}=-\mathbf{C}^{\mathrm{C}} \mathbf{A}_{1}^{\mathrm{C}}=-\mathbf{C}^{\mathrm{C}}\left\{\begin{array}{c}
A_{1}^{\mathrm{C}} \\
-B_{1}^{\mathrm{C}}
\end{array}\right\}
$$

The continuity conditions (11) and (12) can be written as

$$
\begin{array}{ll}
\mathbf{U}^{\mathrm{I}}=\mathbf{U}^{\mathrm{M}}, & \mathbf{T}^{\mathrm{I}}=\mathbf{T}^{\mathrm{M}} \quad \text { on } r=a \\
\mathbf{U}^{\mathrm{M}}=\mathbf{U}^{\mathrm{C}}, & \mathbf{T}^{\mathrm{M}}=\mathbf{T}^{\mathrm{C}} \quad \text { on } r=b
\end{array}
$$

By using Eqs. (A.6) and (A.7), and noting $\lambda=a^{2} / b^{2}$, we can obtain

$$
\begin{aligned}
& \mathbf{A}_{1}^{\mathrm{M}}=\mathrm{S}_{1} \mathbf{A}^{\mathrm{I}}, \quad \mathbf{A}_{-1}^{\mathrm{M}}=a^{2} \mathbf{S}_{-1} \mathbf{A}^{\mathrm{I}} \\
& \mathbf{A}^{\mathrm{I}}=-2 \mathbf{Q}^{-1} \Sigma^{0}
\end{aligned}
$$

where

$$
\begin{aligned}
& \mathbf{S}_{1}=\frac{1}{2}\left[\left(\mathbf{C}^{\mathrm{M}}\right)^{-1} \mathbf{C}^{\mathrm{I}}+\mathbf{I}\right] \\
& \mathbf{S}_{-1}=\frac{1}{2}\left[\left(\mathbf{C}^{\mathrm{M}}\right)^{-1} \mathbf{C}^{\mathrm{I}}-\mathbf{I}\right] \\
& \mathbf{Q}=\mathbf{C}^{\mathrm{M}}\left(\mathbf{S}_{1}+\lambda \mathbf{S}_{-1}\right)+\mathbf{C}^{\mathrm{C}}\left(\mathbf{S}_{1}-\lambda \mathbf{S}_{-1}\right)
\end{aligned}
$$

where $\mathbf{I}$ is the second order unit matrix.

(2) The average strains and average stresses, respectively, in the fiber and matrix of a representative unit cell (Fig. 1)

Taking an average of strains and stresses in the fiber and matrix, respectively, we obtain

$$
\begin{array}{ll}
\overline{\mathbf{Z}^{1}}=-\mathbf{A}^{\mathrm{I}}, & \overline{\mathbf{Z}^{\mathrm{M}}}=-\mathbf{A}_{1}^{\mathrm{M}}=-\mathbf{S}_{1} \mathbf{A}^{\mathrm{I}} \\
\overline{\Sigma^{\mathrm{I}}}=-\mathbf{C}^{\mathrm{I}} \mathbf{A}^{\mathrm{I}}, & \overline{\Sigma^{\mathrm{M}}}=-\mathbf{C}^{\mathrm{M}} \mathbf{A}_{1}^{\mathrm{M}}=-\mathbf{C}^{\mathrm{M}} \mathbf{S}_{1} \mathbf{A}^{\mathrm{I}}
\end{array}
$$

(3) The average strain $\overline{\mathbf{Z}}$ and average stress $\bar{\Sigma}$ in a representative unit cell (Fig. 1)

From Eqs. (A.9) and (A.13) and (A.14)

$$
\begin{aligned}
\overline{\mathbf{Z}} & =\lambda \overline{\mathbf{Z}^{\mathrm{I}}}+(1-\lambda) \overline{\mathbf{Z}^{\mathrm{M}}}=-\left[\lambda \mathbf{I}+(1-\lambda) \mathbf{S}_{1}\right] \mathbf{A}^{\mathrm{I}} \\
& =2\left[\lambda \mathbf{I}+(1-\lambda) \mathbf{S}_{1}\right] \mathbf{Q}^{-1} \Sigma^{0} \\
\bar{\Sigma} & =\lambda \overline{\Sigma^{\mathrm{I}}}+(1-\lambda) \overline{\Sigma^{\mathrm{M}}}=-\left[\lambda \mathbf{C}^{\mathrm{I}} \mathbf{I}+(1-\lambda) \mathbf{C}^{\mathrm{M}} \mathbf{S}_{1}\right] \mathbf{A}^{\mathrm{I}} \\
& =2\left[\lambda \mathbf{C}^{\mathrm{I}} \mathbf{I}+(1-\lambda) \mathbf{C}^{\mathrm{M}} \mathbf{S}_{1}\right] \mathbf{Q}^{-1} \Sigma^{0}
\end{aligned}
$$

where $\mathbf{I}$ is the second order unit matrix.

(4) The equations to predict the effective electroelastic moduli

According to the generalized self-consistent theory, the average stress and strain in a representative unit cell are identical to those in the entire composites. For a representative unit cell, we can prove that the following three approaches are equivalent for predicting the effective electroelastic moduli. 
(1) Use Eq. (63)

$$
\bar{\Sigma}=\mathbf{C}^{\mathrm{C}} \overline{\mathbf{Z}}
$$

The substitution of Eqs. (A.15) and (A.16) into Eq. (A.17) yields

$$
\left[\lambda \mathbf{C}^{\mathrm{I}} \mathbf{I}+(1-\lambda) \mathbf{C}^{\mathrm{M}} \mathbf{S}_{1}\right] \mathbf{A}^{\mathrm{I}}=\mathbf{C}^{\mathrm{C}}\left[\lambda \mathbf{I}+(1-\lambda) \mathbf{S}_{1}\right] \mathbf{A}^{\mathrm{I}}
$$

from which, we obtain

$$
\mathbf{C}^{\mathrm{C}}=\left[\lambda \mathbf{C}^{\mathrm{I}} \mathbf{I}+(1-\lambda) \mathbf{C}^{\mathrm{M}} \mathbf{S}_{1}\right]\left[\lambda \mathbf{I}+(1-\lambda) \mathbf{S}_{1}\right]^{-1}
$$

(2) Use Eq. (66)

$$
\overline{\mathbf{Z}}=\mathbf{Z}^{0}
$$

or

$$
\Sigma^{0}=\mathbf{C}^{\mathrm{C}} \overline{\mathbf{Z}}=\mathbf{C}^{\mathrm{C}} \mathbf{Z}^{0}
$$

The substitution of Eq. (A.15) into Eq. (A.21) yields

$$
\begin{aligned}
& 2 \mathbf{C}^{\mathrm{C}}\left[\lambda \mathbf{I}+(1-\lambda) \mathbf{S}_{1}\right] \mathbf{Q}^{-1} \Sigma^{0}=\Sigma^{0} \\
& 2 \mathbf{C}^{\mathrm{C}}\left[\lambda \mathbf{I}+(1-\lambda) \mathbf{S}_{1}\right]=\mathbf{Q}=\mathbf{C}^{\mathrm{M}}\left(\mathbf{S}_{1}+\lambda \mathbf{S}_{-1}\right)+\mathbf{C}^{\mathrm{C}}\left(\mathbf{S}_{1}-\lambda \mathbf{S}_{-1}\right)
\end{aligned}
$$

Substituting Eqs. (A.10) and (A.11) into Eq. (A.23), we can obtain

$$
\mathbf{C}^{\mathrm{C}}=\left[\lambda \mathbf{C}^{\mathrm{I}}+(1-\lambda) \mathbf{C}^{\mathrm{M}} \mathbf{S}_{1}\right]\left[\lambda \mathbf{I}+(1-\lambda) \mathbf{S}_{1}\right]^{-1}
$$

which is in exact agreement with Eq. (19).

(3) Use Eq. (67)

$$
\bar{\Sigma}=\Sigma^{0}
$$

Similarly, we can also obtain Eq. (A.19) or Eq. (A.24).

It is seen that the three approaches are equivalent and the fact shows that generalized self-consistent approach is a better one than the dilute and self-consistent approaches for predicting effective electroelastic moduli.

\section{References}

Aboudi, J., 1991. Mechanics of Composite Materials: A Unified Micromechanical Approach. Elsevier, The Netherlands.

Benveniste, Y., 1993. Exact results in the micromechanics of fibrous piezoelectric composites exhibiting pyroelectricity. Proc. R. Soc. Lond. A441, 59-81.

Christensen, R.M., Lo, K.H., 1979. Solutions for effective shear properties in three phase sphere and cylinder models. J. Mech. Phys. Solids 27, 315-330.

Dunn, M.L., Taya, M., 1993. Micromechanics predictions of the effective electroelastic moduli of piezoelectric composites. Int. J. Solids Struct. 30 (2), 161-175.

Eshelby, J.D., 1957. The determination of the elastic field of an ellipsoidal inclusion, and related problems. Proc. R. Soc. Lond. A241, 376.

Eshelby, J.D., 1959. The elastic field outside an ellipsoidal inclusion. Proc. R. Soc. Lond. A252, 561.

Gandhi, M.V., Thompson, B.S., 1992. Smart materials and structures. Chapman and Hall, London.

Hashin, Z., Rosen, B.W., 1964. The elastic moduli of fiber reinforced materials. J. Appl. Mech. 31, $223-232$.

Honein, T., Honein, B., Honein, E., Herrmann, G., 1990. On piezoelectric circular inclusions. In: Hsieh, R.K.T. (Ed.), Mechanical Modelling of Electromagnetic Materials, Elsevier, Amsterdam. 
Huang, Y., Hu, K.X., Wei, X., Chandra, A., 1994. A generalized self-consistent mechanics method for composite materials with multiphase inclusion. J. Mech. Phys. Solids 42, 491-504.

Huang, Y., Hu, K.X., 1995. A generalized self-consistent mechanics method for solids containing elliptical inclusions. ASME J. Appl. Mech. 62, 566-572.

Jiang, C.P., Cheung, Y.K., 1998. A fiber/matrix/composite model with a combined confocal elliptical cylinder unit cell for predicting the effective longitudinal shear modulus. Int. J. Solids Struct. 35 (30), 3977-3987.

Luo, H.A., Weng, G.J., 1987. On Ashley's inclusion problem in a three-phase spherically concentric solid, and a modification of MoriTanaka's method. Mech. Mater. 6, 347-361.

Luo, H.A., Weng, G.J., 1989. On Eshelby's S-tensor in a three-phase cylindrically concentrated solid, and the elastic moduli of fiberreinforced composites. Mech. Mater. 8, 77-88.

Mori, T., Tanaka, K., 1973. Average stress in the matrix and average elastic energy of materials with misfitting inclusions. Acta Metall. 21, 571-574.

Pak, Y.E., 1992. Circular inclusion problem in antiplane piezoelectricity. Int. J. Solids Struct. 29, 2403-2419.

Sosa, H.A., 1991. Plane problems in piezoelectric media with defects. Int. J. Solids Struct. 28, 491-505.

Tiersten, H.F., 1969. Linear Piezoelectric Plate Vibrations. Plenum Press, New York.

Wang, B., 1992. Three-dimensional analysis of an ellipsoidal inclusion in a piezoelectric material. Int. J. Solids Struct. $29,293-308$.

Whitney, J.M., Riley, M.B., 1966. Elastic properties of fiber reinforced composite materials. AIAA J 4 (9), $1537-1542$.

Zhang, T.Y., Qian, C.F., Tong, P., 1998. Linear electroelastic analysis of a cavity or a crack in a piezoelectric material. Int. J. Solids Struct. 35, 2121-2149. 